\title{
The Contribution of Clinical Trials in Psychiatry: A Basic Science of Clinical Care
}

\author{
Andrew A. Nierenberg, MD
}

To paraphrase Dickens, it is the best of times and the worst of times in psychiatric research. It is the best of times because of an explosion in basic brain science relevant for psychiatry: neurophysiology, neurocircuitry, neurogenesis, neuroprotection, structural and functional neuroimaging, genomics, genetic epidemiology, pharmacogenomics, proteomics, and metabolomics. It is the worst of times because of the dearth of clinical trials that assess new psychiatric interventions: few new medications or novel psychotherapies are being developed or approved for depression, bipolar disorder, schizophrenia, or anxiety disorders. Non-industry funding for clinical trials has, with few exceptions, diminished substantially in the past 5 years.

Similar to what had occurred in internal medicine a generation ago, psychiatry is (appropriately) concerned with understanding pathophysiology to identify fundamental defects that can lead to new therapeutic targets and new therapeutics. But the number of psychiatric clinical trials published in the literature that impact practice has decreased. Furthermore, the value of clinical trials has been under assault, fueled by cynicism that negative results have been withheld by pharmaceutical companies and that these same companies have emphasized minimal benefits while hiding the risks of their products. Critics have castigated the pharmaceutical companies for pur- suing profit at the expense of patients' health. ${ }^{1-3}$ With these issues at the forefront, what then (if any) is the continuing value of clinical trials?

Clinical trials generate essential, albeit imperfect, evidence for clinicians to make informed decisions for the care of their patients. Clinical trials are the ultimate method to test if therapeutic interventions work and provide important data to guide clinicians to assess benefit/risk ratios. These trials put interventions to the test by minimizing bias (through randomization, controls, and blinding when appropriate) and ask "is the study intervention better than alternatives (placebo or active controls)"? Treatments that appear theoretically appealing must pass through the crucible of clinical trials.

Clinical trials provide the evidence for "evidence based medicine". The phrase "evidence based medicine" is, however, peculiar. What is the alternative? Use non-evidence based medicine $?^{4}$ Clinicians (should) practice psychiatry informed by clinical trials ("hard data"), clinical experience, and clinical reasoning (and in reality, use stories from colleagues). ${ }^{5-8}$ But investigators limit the clinical utility of the results of clinical trials by reporting mean changes on scales without relevant data that would identify those patients who might benefit or worsen during treatment. ${ }^{9}$

Generalizability is another issue. While some researchers have found that research and clini-

Dr. Nierenberg is professor of psychiatry at Harvard Medical School, co-director of the Bipolar Clinic and Research Program, and associate director of the Depression Clinical and Research Program at Massachusetts General Hospital (MGH) in Boston.

Faculty Disclosures: Dr. Nierenberg consulted to or served on the advisory boards of Abbott, Appliance Computing, Inc., Brain Cells, Inc., Bristol-Myers Squibb, Eli Lilly, EpiQ, Forest, GlaxoSmithKline, Janssen, Jazz, Merck, Novartis, Pam Labs, Pfizer, PGx Health, Pharmaceutica, Schering-Plough, Sepracor, Shire, Somerset, Takeda, and Targacept; he has received research support from Cederroth, Cyberonics, Forest, Medironics, NARSAD, NIMH, Ortho-McNeil-Janssen, Pam Labs, Pfizer, Shire, and the Stanley Foundation through the Broad Institute; he has received past support from Bristol-Myers Squibb, Cederroth, Eli Lilly, Forest, GlaxoSmithKline, Janssen, Pfizer, Lictwer Pharma, and Wyeth; he has received honoraria from the MGH Psychiarry Academy (MGHPA activities are supported through Independent Medical Education grants from Astra Zeneca, Eli Lilly, and Janssen; he earns fees for editorial functions for CNS Spectrums through MBL Communications, Inc., and Psychiatric Annals through Slack, Inc.; he receives honoraria as a CME Executive Director for the Journal of Clinical Psychiatry through Physicians Postgraduate Press; he has been on the speaker's bureaus of Bristol-Myers Squibb, Cyberonics, Eli Lilly, Forest, GlaxoSmithKline, and Wyeth; he has received royalties from Cambridge University Press and Belvoir Publishing; he owns stock options in Appliance Computing, Inc.; and owns the copyrights to the Clinical Positive Affect Scale and the MGH Structured Clinical Interview for the Montgomery Asberg Depression Scale, exclusively licensed to the MGH Clinical Trials Network and Institute. 
cal patient populations are similar, ${ }^{10-12}$ others have found that those who seek clinical treatment differ substantially from those who participate in research trials. ${ }^{13}$ Given that there may be important differences between clinical and research populations, clinicians tend to be cautious when generalizing research findings to daily practice and, by integrating their clinical experience with information from randomized, clinical trials (RCTs), avoid turning evidence-based medicine into "evidence-biased medicine". ${ }^{14}$ Other critiques of RCTs include: insensitive measures, problems with research raters, and the use of designs meant for medication registration rather than for guiding clinical practice. ${ }^{15,16}$ Nevertheless, RCTs, while imperfect, serve as an essential basis for informing clinical practice. The results should not be applied mindlessly and interpretation of results should take into account their limited external validity.

The majority of published psychiatric clinical trials are funded by and conducted for pharmaceutical companies. Companies conduct those trials that they deem in their best interest and consistent with their business models. Pharmaceutical companies are the source of most new medications in psychiatry and need to conduct those trials that ultimately will serve the public and their shareholders-a model that has been largely successful. Few, if any, psychiatric interventions originate with non-industry sources. Pharmaceutical companies will tend to avoid those clinical trials that might damage their business and companies frequently avoid those clinical trials that directly compare medications that might risk making their product appear less competitive. The challenge is for companies to conduct clinical trials that not only get medications to market (registration trials) but for the field to conduct those trials that help with daily clinical practice, including the development and testing of psychosocial interventions. Foundations and governments play an essential role for funding these trials.

The National Institutes of Mental Health in the United States recently completed three large effectiveness trials that were planned in the late 1990's: CATIE, STEP-BD, and STAR*D to compare or eval- uate interventions for schizophrenia, bipolar disorder, and depression, respectively. Each study has its strengths and limitations, supporters and detractors. The overall mission of these studies was to conduct clinical trials that would not have been supported by the pharmaceutical industry and that would advance the treatment of serious mental illnesses. These hybrid effectiveness studies provide a different form of information than registration trials and provide additional evidence to guide and inform clinical practice.

Psychiatric clinical trials designed with internal and external validity that inform clinical practice are expensive to conduct but essential if clinicians are to have the data needed to provide optimal care for their patients. We will need continued funding and manpower to conduct clinical trials that will enhance public health. Continued funding needs the support of the public and especially advocacy groups. Continued investments in research training programs that develop clinical researchers are also needed to continue to serve the public interest. CNS

\section{REFERENCES}

1. Avorn J. Powerful Medicines: The Benefits, Risks, and Costs of Prescription Drugs. New York, NY: Vintage; 2005.

2. Angell M. The Truth About the Drug Companies: How They Deceive Us and What to Do About it. New York, NY: Random House; 2005.

3. Kassirer J. On the Take: How Medicine's Complicity with Big Business Can Endanger Your Health. New York, NY: Oxford University Press; 2005.

4. Isaacs D, Fitzgerald D. Seven alternatives to evidence based medicine. $B M J$ 1999;319:1618.

5. Devereaux PJ, Yusuf S. The evolution of the randomized controlled trial and its role in evidence-based decision making. J Intern Med. 2003:254:105-113.

6. Golder EM, Bilsker D. Evidence-based psychiatry. Can J Psychiatry. 1995:40:97-101.

7. Sackett DL. Evidence-based medicine. Semin Perinatol. 1997;21:305.

8. Sackett DL. Rosenberg WM. On the need for evidence-based medicine. J Public Health Med. 1995; 17:330-334.

9. Horwitz RI, Singer BH, Makuch RW. Viscoli CM. Can treatment that is helpful on average be harmful to some patients? J Clin Epidemiol. 1996;49:395-400

10. Carroll KM, Nich C, McLellan AT, McKay JR, Rounsaville BJ. 'Research' versus 'realworld' patients: representativeness of participants in clinical trials of treatments for cocaine dependence. Drug Alcohol Depend. 1999-54:171-177

11. Rapaport MH, Frevert T, Babior S, Zisook S, Judd LL. A comparison of demographic variables, symptom profiles, and measurements of functioning in symptomatic volunteers and an outpatient clinical population. Psychopharmacol Bull. 1995;31:111-114.

12. Stirman SW, DeRubeis RJ, Crits-Christoph P. Brody PE. Are samples in randomized controlled trials of psychotherapy representative of community outpatients? A new methodology and initial findings. J Consult Clin Psychol. 2003:71:963-972.

13. Braslow JT, Duan N, Starks SL, Polo A, Bromley E, Wells KB. Generalizability of studies on mental health treatment and outcomes, 1981 to 1996. Psychiatr Serv. 2005:56:1261-1268.

14. Schelling FA. Clinical trials: deliberations on their essence and value. J Eval Clin Pract. 2004:10:291-296.

15. Fava GA. The intellectual crisis of psychiatric research. Psychother Psychosom. 2006; $75: 202-208$

16. Wise TN. Curiosity and crisis. Psychother Psychosom. 2006;75:199-201 


\section{THE NEXT GENERATION OF BLACK BOOKS NOW AVAILABLE}
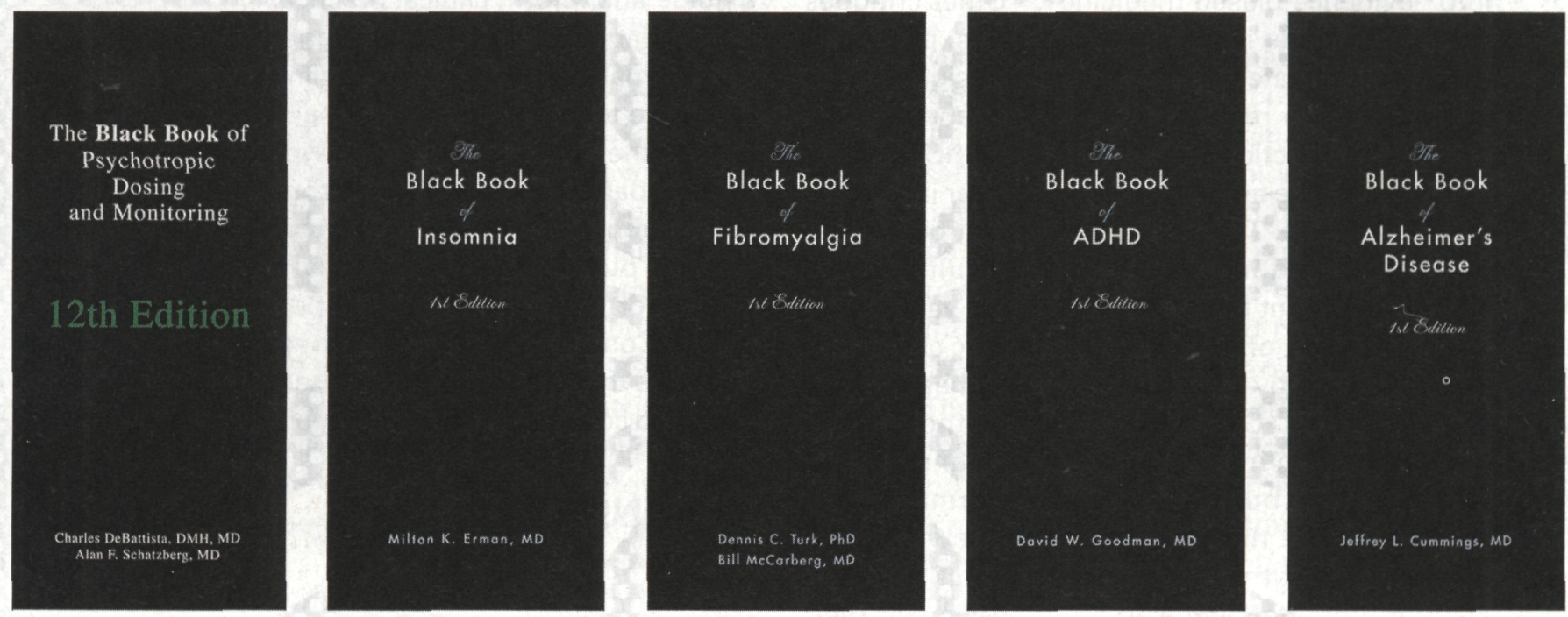

\section{ORDER YOUR BLACK BOOK COPIES ONLINE}

The Black Book of Psychotropic Dosing and Monitoring

The Black Book of Insomnia

The Black Book of Fibromyalgia

The Black Book of ADHD

The Black Book of Alzheimer's Disease

\section{Coming Soon-The Black Book of CNS Drug Interactions}

Spiral bound print versions of each Black Book are now available for only $\$ 12.99$ plus $S \& H$.*

Interactive e-versions for your desktop and/or smart phone are coming soon.

To order, please visit Customer Service at www.cnsspectrums.com

*Please allow 6-8 weeks for delivery

Please contact the publisher, dlb@mblcommunications.com, for more information or call 212-328-0800 x266 